\title{
Hypersensitivity Reactions to Proton Pump Inhibitors
}

\section{Carla Lombardo, MD Patrizia Bonadonna, MD*}

\author{
Address \\ *Allergy Unit, Azienda Ospedaliera Universitaria Integrata di Verona, Pz.le Aristide \\ Stefani 1, 37126, Verona, Italy \\ Email: patrizia.bonadonna@ospedaleuniverona.it
}

Published online: 21 March 2015

(C) Springer International Publishing AG 2015

This article is part of the Topical Collection on Drug Allergy

Keywords Proton pump inhibitors - Drug allergy - Anaphylaxis - Adverse drug reaction - Drug hypersensitivity

\section{Opinion Statement}

Proton pump inhibitors (PPIs) are drugs widely used and usually well tolerated. However, cases of immediate or cell-mediated hypersensitivity reactions due to all PPIs, with the exception of the newest dexlansoprazole and tenatoprazole, have been described. In the case of suspected IgE-mediated reaction skin test (prick test and intradermal test) with nonirritant drug concentration published is safe and highly specific (100\%) with a PPV of $100 \%$. Thus, oral provocation test should be performed only in case of negative results to rule out definitely the diagnosis. In the case of possible cell-mediated hypersensitivity reaction, a delayed reading of intradermal test, at least after 24 and $48 \mathrm{~h}$, and patch test should be performed, but we do not have standardized procedures so far. Cross-reactivity among all PPIs is not a dogma, in fact, three patterns of cross-reactivity have been described. Thus, in patients with ascertained allergy to a PPI, a complete evaluation (skin test and oral provocation test) of all five PPIs available helps to identify a safe alternative.

\section{Introduction}

Proton pump inhibitor (PPIs) drugs are potent inhibitors of gastric acid secretion, which block the hydrogenpotassium adenosine triphosphatase enzyme system $\left(\mathrm{H}^{+} / \mathrm{K}^{+}\right.$-ATPase). These drugs are widely used for the treatment of gastrointestinal diseases, such as gastroesophageal reflux or peptic ulcer. They are also frequently used in combination with other drugs, for the eradication of Helicobacter pylori, and to prevent gastric damages due to corticosteroids and nonsteroidal antiinflammatory drugs (NSAIDs). PPIs are frequently used without medical prescription, and they are often not recorded in the medical history.

Since the first PPI omeprazole was introduced in 1989, other six PPIs have been developed: pantoprazole, esomeprazole, rabeprazole, lansoprazole, R-enantiomer dexlansoprazole, and tenatoprazole (not available in Italy). PPIs are usually well tolerated, with a low risk of minor side effects, approximately of 1-3\% [1]. The most common side effects induced by PPIs are diarrhea, headache, nausea, dizziness, and skin rash. 
Serious adverse hypersensitivity reactions to PPIs, both nonallergic (cytopenia, vasculitis, acute interstitial nephritis, hepatitis, and cutaneous lupus erythematosus) and allergic (anaphylaxis, contact and photoallergic dermatitis, drug rash with eosinophilia and systemic symptoms (DRESS), StevensJohnson syndrome, and toxic epidermal necrolysis), have been reported $[1,2 \bullet, 3-6,7 \bullet, 8-14]$. Moreover, since most patients are on long-term therapy with PPI, safety concerns about adverse effects have been arisen $[1,15 \bullet]$.

This review will focus on allergic hypersensitivity reactions to PPI and the related diagnostic approach and treatment options.

\section{Chemical structure of PPIs and hints of pharmacokinetic}

The currently available PPIs have a common chemical structure, represented by a benzimidazole ring plus a pyridine ring, varying only in the side chain substituted on both moieties.

Thus, omeprazole and pantoprazole have respectively a methoxy and a difluoromethoxy chain in their benzimidazole rings, whereas lansoprazole and rabeprazole change the pyridine ring, where there are trifluoroethoxy and methoxypropoxy chain respectively.

Omeprazole, lansoprazole, and rabeprazole have a relatively short plasma half-life (1-2 h), while esomeprazole, the S-enantiomer of omeprazole, is metabolized more slowly than omeprazole. Overall, all these PPIs do not provide a 24-hour control of gastric acidity [16].

Tenatoprazole has a fivefold to sevenfold longer half-life and, unlike other PPIs, is not a substituted benzimidazole, but it is characterized by imidazopyridine ring [16].

Dexlansoprazole, the R-enantiomer, is equipotent to lansoprazole in inhibiting $\mathrm{H}^{+} / \mathrm{K}^{+}$-ATPase; however, as dexlansoprazole, it shows a slower clearance with corresponding higher circulating plasma concentrations and longer half-life because it is commercialized as a modified release formulation that uses an innovative dual delayed release (DDR) delivery system [17]. The DDR formulation results in a two-phase plasma concentration profile, with two distinct peaks: the first peak occurs 1 to $2 \mathrm{~h}$ after administration, followed by a

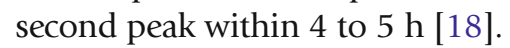

PPIs are prodrugs, formulated as delayed-release enteric-coated preparation, and they are mainly absorbed in the small intestine [16]. After absorption, within the acid environment of parietal cells, PPIs undergo to a protonation in both pyridine and benzimidazole or imidazopyridine ring that leads to the formation of the active sulfenamide derivative, which binds covalently to cysteine moieties of the $\mathrm{H}^{+} / \mathrm{K}^{+}$-ATPase. Once inhibition has taken place, recovery of acid secretion can occur only after regeneration or synthesis of new $\mathrm{H}^{+} / \mathrm{K}^{+}$ATPase [16].

\section{Safety of long-term treatment with PPIs}

\section{PPIs may facilitate comorbidities}

A theoretical interaction between PPIs and clopidogrel, due to the competitive binding at cytochrome (CYP) 450, has been highlighted. This may reduce the conversion of clopidogrel in its active metabolite, thus leading to an increased 
risk of cardiovascular events. However, results of clinical studies are still inconsistent, and it is not possible to exclude or confirm a clinically significant interaction. Indeed, FDA has currently advised against the use of omeprazole and esomeprazole in patients taking clopidogrel [15•].

PPIs have also been implicated in the development of osteoporosis and a possible increased risk of bone fractures, since early studies have shown a trend toward increased risk of fracture among people taking long-term therapy with PPIs $[19,20]$. The possible mechanisms might be a consequence of a decreased calcium absorption due to the increased gastric $\mathrm{pH}$ or a diminished osteoclast function caused by the inhibition of the vacuolar proton pump [15•].

Other studies did not confirm this association, and a recent meta-analysis has not established a clear link between PPIs use and risk of fractures and has also excluded a dose-dependent or duration-dependent effect [21-23]. This discrepancy might be explained by the fact that early studies probably suffered from an appropriate stratification of other possible risk factors associated with osteoporosis.

Some case reports and small case series have also suggested a risk of hypomagnesemia in patients treated for long periods with PPIs, mainly elderly and those treated with diuretic and/or digoxin, which prompted in 2011 the FDA to issue a warning about the risk of hypomagnesemia in patients chronically treated with PPIs $[15 \bullet, 24-26]$. On the other hand, the mechanism of PPIsinduced hypomagnesemia remains still unknown, although it seems to be related to a reduced intestinal absorption of magnesium. Current knowledge suggests that it would be reasonable to check blood level of magnesium in patients who require long-lasting therapy with PPIs [15•]. [1].

Chronic therapy with PPIs is not associated with vitamine B12 deficiency

Other possible safety concerns include a supposed, but not proven, increased risk of enteric infections (including Clostridium difficile), which might be a consequence of the alteration of the intestinal bacteria microbiota, and an increased risk of community acquired pneumonia following the increased bacterial colonization of the stomach facilitated by hypochlorhydria [1, 27-29].

Long-term use of PPIs has been in principle supposed to accelerate the progression of $\mathrm{H}$. Pylori-associated chronic gastritis to gastric atrophy, which may evolve in intestinal metaplasia and gastric cancer, but currently, there is no convincing study of this [1]. Prolonged PPI therapy is associated with the development of parietal cell hyperplasia, with a fourfold incidence of fundic gland polyps, regardless of the presence of H. Pylori infection, conditions that rapidly regress after $H$. Pylori is eradicated or PPIs are discontinued [30]. Fundic gland polips may rarely became dysplastic but almost exclusively in patients with familial adenomatous polyps [1,31].

\section{PPIs may facilitate developing of food and drug allergy}

Therapy with antiulcer drugs is indicated as a possible cause of allergic sensitization to foods. A low gastric PH (between 1 and 3.5) is indeed necessary to activate gastric pepsin and duodenal secretin and also to stimulate the release of pancreatic enzymes. When anti-acid drugs inhibit acid gastric secretion, foodrelated allergens may remain intact and absorbed, facilitating an allergic sensitization $[32,33]$. 
Anti-acid therapy is also considered a possible cofactor, together with exercise, anti-inflammatory drug therapy and alcohol, in decreasing the threshold dose of allergens able to elicit anaphylaxis. This may be especially relevant in patients with wheat-dependent exercise-induced anaphylaxis (WDEIA) or in patients with oral allergy syndrome due to acid-sensitive allergens who might develop systemic symptoms when eating a big amount of allergen while being

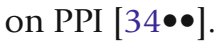

Animal and human studies have confirmed that the use of PPI and other anti-acid increases the risk of sensitization to food allergens and the risk of developing anaphylaxis [35-37].

Moreover, anti-acid therapy has been indicated as a possible risk factor for drug hypersensitivity reactions. In a recent retrospective study involving hospitalized patients, the odds ratio of drug hypersensitivity was 4.35 in PPI-treated patients, compared with matched controls after correcting for confounders [38]. In a murine sensitization model to diclofenac, anti-diclofenac IgE and IgG1 were evidenced only in those mice receiving albumine-coupled diclofenac under PPI-therapy. [39]. It might be speculated that a complete gastric acid suppression, as occurs in long-term PPI-treated patients, may predispose to allergic sensitization as a consequence of the persistence of intermediate drug carrier complexes that allow small molecules to become immunogenic after bounding to a protein carrier (i.e., albumine) [40].

These observations remain at a hypothesis stage and require further researches to better clarify the role of hypochlorhydria and related mechanisms in inducing drug hypersensitivity in humans.

\section{Allergic hypersensitivity reactions}

\section{Type I, IgE-mediated hypersensitivity reactions}

Several reports about hypersensitivity reactions to PPIs are available in literature. Currently, there are 35 reports of type I reactions for a total number of 184 patients with symptoms ranging from mild to life threatening (anaphylaxis) (Table 1).

The first case report of urticaria/angioedema and bronchospasm, which occurred after $2 \mathrm{~h}$ of omeprazole intake in a 44-year-old man, was published only 3 years after the marketing of the drug [41]. However, the author indicated the possibility of a sensitization toward capsule shell, because the patient could tolerate enteric coated granules without the gelatine envelope.

There is only another report of sensitization to additives, which is the case of a cell-mediated sensitization to sodium lauryl sulfate, a preservative held in omeprazole and lansoprazole capsules, in a patient with generalized erythema after omeprazole and lansoprazole intake [42].

Most of case reports and small case series (Table 1) report hypersensitivity reaction (HSR) to omeprazole (74.5\%), while pantoprazole and lansoprazole are the culprit drugs in $12 \%$ of cases each and rabeprazole only in one case $(1.5 \%)$. Two recent large trials showed a different distribution of the frequency

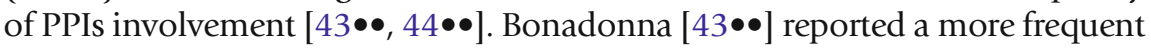
involvement of esomeprazole (30 \%), followed by lansoprazole $(26.4 \%)$, while omeprazole was the culprit drug in $18.9 \%$ of cases; In the population of Kepil Ozdemir study [44••], lansoprazole was responsible of $80 \%$ of cases of HSRs while omeprazole was responsible in $1.5 \%$ of cases. This may reflect a different regional distribution in PPI prescription. 
Table 1. Reports of immediate-type reactions to proton pump inhibitors, skin test results, and cross-reactivity patterns

\begin{tabular}{|c|c|c|c|c|c|c|c|}
\hline $\begin{array}{c}\text { Reference, } \\
\text { Publication Year }\end{array}$ & $\begin{array}{c}\text { Patient } \\
\text { Number }\end{array}$ & Culprit drug & $\begin{array}{c}\text { Main } \\
\text { symptom }\end{array}$ & $\begin{array}{l}\text { Timing of } \\
\text { reaction }\end{array}$ & Drug studied & $\begin{array}{c}\text { Allergic test } \\
\text { With culprit drug }\end{array}$ & $\begin{array}{l}\text { Cross-reactivity } \\
\text { pattern }\end{array}$ \\
\hline Haeney, 1992 [41] & 1 & Omeprazole & Angioedema, urticaria & 2 hours & Omeprazole & OPT: - & p.inor \\
\hline Bowlby, 1994 [88] & 1 & Omeprazole & Anaphylaxis & $1-3 \mathrm{~h}$ hours & Omeprazole & OPT: + & I \\
\hline Ottervanger, $1996[41]$ & 1 & Omeprazole & Anaphylaxis & Immediately & Omeprazole & ST: + & 1 \\
\hline Perez Roldan, 1999 [69] & 1 & Lansoprazole & Glottis edema & $45 \mathrm{~min}$ & Lansoprazole & $\mathrm{NP}$ & l \\
\hline Galindo, 1999 [13] & 1 & Omeprazole & Anaphylaxis & Immediately & $\mathrm{La}, \mathrm{Om}$ & ST:+, ID:+ & Om-La (Whole group ?) \\
\hline Natsch, $2000[70]$ & 2 & $\mathrm{Om}+\mathrm{La}, \mathrm{Pa}$ & Anaphylaxis & $45 \mathrm{~min}$, hours & 1 & 1 & 1 \\
\hline Kaatz, 2001 [89] & 1 & Pantoprazole & Anaphylaxis & & Pantoprazole & ST: -, OPT: + & 1 \\
\hline Fardet, $2002[84]$ & 1 & Pantoprazole & Anaphylaxis & Immediately & $\mathrm{Pa}, \mathrm{La}$ & OPT: + & Selective to Om (Type A) \\
\hline Gonzales, $2002[81]$ & 1 & Omeprazole & Urticaria & $30 \mathrm{~min}$ & $\mathrm{Om}, \mathrm{Pa}, \mathrm{La}$ & ST: + & Om-Pa-La (Whole group ?) \\
\hline Ricciardi, 2003 [71] & 2 & Pantoprazole & Angioedema, urticaria & $45 \mathrm{~min}, 2 \mathrm{~h}$ & 1 & 1 & / \\
\hline Gamboa, $2003[82]$ & 1 & Omeprazole & Angioedema, urticaria & $15 \mathrm{~min}$ & Omeprazole & ST:,+ BAT: + & 1 \\
\hline Kollmeier, $2004[50]$ & 1 & Pantoprazole & Anaphylaxis & 3 hours & Pantoprazole & ID: + & 1 \\
\hline Garmendia Zallo, 2004 [51] & 1 & Omeprazole & Angioedema, Urticaria & 2 hours & $\mathrm{Om}, \mathrm{Pa}, \mathrm{La}$ & ST:-, ID:+ & Om-Pa-La (Whole group ?) \\
\hline Porcel, 2005 [74] & 1 & Lansoprazole & Angioedema, Urticaria & $30 \mathrm{~min}$ & $\mathrm{Om}, \mathrm{Pa}, \mathrm{Es}, \mathrm{La}, \mathrm{Ra}$ & ST: + & La-Ra (type B) \\
\hline Gratacos, $2005[72]$ & 1 & Pantoprazole & Anaphylaxis & 4 hours & 1 & 1 & / \\
\hline Demirkan, 2006 [90] & 1 & Lansoprazole & Anaphylaxis & $20 \mathrm{~min}$ & $\mathrm{La}, \mathrm{Om}, \mathrm{Pa}$ & ST:+ & Selective to Lansoprazole (type $B$ ?) \\
\hline Confino-Cohen, 2006 [83] & 1 & Omeprazole & Anaphylaxis & $40 \mathrm{~min}$ & $\mathrm{Om}, \mathrm{Pa}$ & ST:+ & Omepraz/Pantopraz (type A?) \\
\hline Perez-Pimiento, 2006 [75] & 1 & Lansoprazole & Anaphylaxis & $30 \mathrm{~min}$ & $\mathrm{La}, \mathrm{Ra}, \mathrm{Om}, \mathrm{Pa}$ & ST:+, OPT:+ & Type B \\
\hline Stefanaki, $2008[77]$ & 1 & Omeprazole & Anaphylaxis & $15 \mathrm{~min}$ & $\mathrm{Om}, \mathrm{Pa}, \mathrm{Es}, \mathrm{La}, \mathrm{Ra}$ & ST:+ & Selective to omeprazole \\
\hline Garrido S, 2008 [52] & 1 & Omeprazole & Anaphylaxis & 1 hour & $\mathrm{Om}, \mathrm{Pa}, \mathrm{Es}, \mathrm{La}, \mathrm{Ra}$ & ST:+, ID:+ & Whole group \\
\hline Vovolis, 2008 [53] & 2 & Omeprazole & Anaphylaxis & $15 \mathrm{~min}, 1$ hour & $\mathrm{Om}, \mathrm{Pa}, \mathrm{Es}, \mathrm{La}, \mathrm{Ra}$ & ST:+, ID:+ & 1:Selective to Om; 2 : selective Om-Pa \\
\hline Lobera, 2009 [47] & 9 & Omeprazole & $\begin{array}{l}7 \mathrm{pz} \text { urticaria } \\
2 \mathrm{pz} \text { anaphylaxis }\end{array}$ & 30 min- 4 hours & $\mathrm{Om}, \mathrm{Pa}, \mathrm{La}$ & ST/ID:+,or OPT:+ & $\begin{array}{l}6 \text { patients: Om-Pa (Type A?); } \\
1 \text { patient: Om-La (Whole group?) }\end{array}$ \\
\hline Vlahos, 2009 [91] & 1 & Lansoprazole & Kounis Syndrome & $10 \mathrm{~min}$ & $\mathrm{Om}, \mathrm{Pa}, \mathrm{La}$ & ST: + & Selective to La (Type B?) \\
\hline Tayman, 2009 [46] & 1 & Omeprazole & Anaphylaxis & 2 hours & $\mathrm{Om}, \mathrm{La}$ & ST:+, ID: + & Om-La (Whole group?) \\
\hline Sobrevia Elfau, 2010 [54] & 5 & Omeprazole & $4 \mathrm{pz}$ Anaphylaxis, $1 \mathrm{pz}$ urticaria & 5 min- 2 hours & $\mathrm{Om}, \mathrm{Pa}$, Es, La, Ra & ST:+, ID: + & Whole group \\
\hline Vovolis, $2010[76]$ & 1 & Rabeprazole & Anaphylaxis & $30 \mathrm{~min}$ & Om, Pa, Es, La, Ra & ST:+, ID:+ & Selective to Ra \\
\hline Lai, $2011[92]$ & 1 & Pantoprazole & Anaphylaxis & $5 \mathrm{~min}$ & Pantoprazole & ST: + & 1 \\
\hline Perez-Ezquerra, 2011 [78] & 1 & Omeprazole & Severe Angioedema & $30 \mathrm{~min}$ & $\mathrm{Om}, \mathrm{Pa}, \mathrm{La}, \mathrm{Ra}$ & ST: +, ID:+ & Whole group \\
\hline Aksu, $2011[55]$ & 1 & Lansoprazole & Angioedema/urticaria & 2 hours & $\mathrm{La}, \mathrm{Om}$ & OPT: + & Selective to La (or Type B?) \\
\hline Bonadonna, 2012 [43] & 53 & All PPIs & $\begin{array}{l}44 \mathrm{pz} \text { mild-moderate } \\
9 \mathrm{pz} \text { anaphylaxis }\end{array}$ & / & Om, Pa, Es, La, Ra & SP/ID:+, or OPT:+ & Type A and Type B \\
\hline Karabakac, 2012 [79] & 1 & Lansoprazole & Angioedema/urticaria & $30 \mathrm{~min}$ & Om, Pa, Es, La, Ra & SPT:+ & Selective to lansoprazole \\
\hline Choi, 2012 [73] & 2 & $\mathrm{La}, \mathrm{Om}$ & Anaphylaxis & $10 \mathrm{~min}, 30 \mathrm{~min}$ & 1 & 1 & 1 \\
\hline Razzak, 2012 [48] & 8 & Omeprazole & $\begin{array}{l}4 \mathrm{pz} \text { urticaria } \\
4 \mathrm{pz} \text { anaphylaxis }\end{array}$ & - & $\mathrm{Om}, \mathrm{Pa}$ & ID: +, or OPT: + & Omepraz/Pantopraz (type A?) \\
\hline Kepil Ozdemir, 2013 [44] & 65 & All PPI & $\begin{array}{l}32 \mathrm{pz} \text { angioedema/urticaria } \\
33 \mathrm{pz} \text { anaphylaxis }\end{array}$ & $\begin{array}{l}49 \mathrm{pz}<1 \text { hour } \\
16 \mathrm{pz}: 1-24 \text { hours }\end{array}$ & Om, Pa, Es, La, Ra & ST/ID:+, or OPT:+ & Mainly lansoprazole-pantoprazole \\
\hline Sanchez-Morillas, 2014 [49] & 11 & Omeprazole & $\begin{array}{l}7 \mathrm{pz} \text { angioedema/urticaria } \\
4 \mathrm{pz} \text { anaphylaxis }\end{array}$ & $\begin{array}{l}5 \mathrm{pz} \text { : immediate } \\
6 \mathrm{pz}:>1 \text { hour }\end{array}$ & Om, $\mathrm{Pa}$, Es, La, Ra & ST/ID:+,or OPT:+ & Mainly Whole group \\
\hline
\end{tabular}

In gray color: papers with complete evaluation of cross-reactivity among all PPIs

Type A cross-reactivity among omeprazole, pantoprazole, and esomeprazole, Type $B$ cross-reactivity between lansoprazole and rabeprazole, Whole group cross-reactivity among all PPIs, Om omeprazole, Pa pantoprazole, Es esomeprazole, La lansoprazole, Ra rabeprazole

a Possible allergy to the capsule shell

There are no reported cases of HSRs to dexlansoprazole or tenatoprazole.

An extensive review of the literature on PPIs HSRs was published in 2013. Bose et al. evaluated all case reports and case series published, analyzing for each case demographic, clinical, and diagnostic aspects, and they found that $86 \%$ of cases were type I, IgE-mediated HSRs to PPIs [45].

Almost all reports involve adult patients, with the exception of a case of anaphylaxis in a 14-year-old child that appeared $2 \mathrm{~h}$ after omeprazole intake [46].

The mean age of the 118 patients evaluated in the above mentioned review was $46 \pm 13$ years, according to the mean age reported in other papers ranging from 42 to 54 years $[43 \bullet \bullet, 44 \bullet \bullet, 45,47-49]$. This data obviously reflect the more frequent chronic use of PPIs in this age group or an "as needed" use of these drugs, which might favor an allergic sensitization. Female gender was

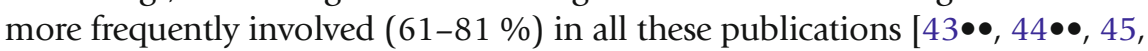
47-49].

Mucocutaneous symptoms (urticaria in $54 \%$ of cases and angioedema in $38 \%$ of cases) were reported as the most frequent manifestation, while hypotension occurred in only $23 \%$ of cases [45]. 
Taking into account all the papers published until now (Table 1), including the two large trials $[43 \bullet \bullet, 44 \bullet \bullet]$, life threatening reactions appear to be frequent, occurring in up to $41.30 \%$ of patients, while urticaria/angioedema occurs in up to $57.6 \%$ of cases. This is a very important point, and prescribers should be aware of this, mainly when they have to prescribe PPIs to patients with history of reaction to NSAIDs or antibiotics during $H$. pylori eradication, where it is important to rule out allergy to PPIs.

Another important point of PPIs HSR is the latency time between the last drug intake and symptom appearance. Looking at the literature, it is clear that type I HSRs to PPIs usually occur within $1 \mathrm{~h}$, also in case of severe anaphylaxis, but there are reports of anaphylactic reactions beginning up to $3 \mathrm{~h}$ after PPI intake $[46,47,50-55]$. This observation was also confirmed in one large study where 16 patients $(24.6 \%)$ had reactions in $1-24 \mathrm{~h}$.

A possible explanation might be found in the formulation of oral PPIs that are available as delayed release, enteric-coated tablets or capsules that protect PPIs from premature acid degradation in the stomach so that absorption can occur in the proximal small intestine, and this may delay the onset of symptoms.

In a case of recurrent delayed anaphylaxis to pantoprazole, it was hypothesized that the unusual timing of reactions might be explained by variations in the metabolic pathways of cytochrome P450 enzyme, so poor metabolizers could suffer an accumulation of drug as a result of a decreased oral clearance and prolonged plasma half-life [50].

Delayed HSRs to PPIs are less frequently reported in literature (Table 2). The first report of a delayed HSR, published in 1992, was a toxic epidermal necrolysis in a 72-year-old woman after 2 weeks of therapy with omeprazole [8]. Afterward, other case reports of epidermal necrolysis and severe exfoliative dermatitis caused by omeprazole, lansoprazole, and esomeprazole have been published [10, 48, 56-58].

One case of DRESS after 20 days of treatment with esomeprazole was published in 2007 [9]. In this paper, a cross-reactivity among esomeprazole, omeprazole, and pantoprazole, but not rabeprazole, was documented by patch test.

There is only one case of Steven-Johnson syndrome and toxic hepatitis published in Spanish language on 2009 [59]. PPIs may also cause photoallergic dermatitis and fixed drug eruption (FED) [12, 60, 61].

Five cases of occupational airborne contact dermatitis caused by lansoprazole, pantoprazole, and omeprazole in pharmaceutical industry workers have been reported so far [11, 62-65].

Ghatam et al. have recently published a large study involving 96 workers who reported possible allergic symptoms resulting from occupational exposure to omeprazole during the manufacturing process. Part of the patients underwent patch test and lymphocyte transformation test (LTT) which associated and confirmed allergy in $40 \%$ of patients [65]. The authors also confirmed the relevant sensitizing capacity of omeprazole by performing a predictive test on guinea pigs as previously demonstrated by Hausen et al. [66]. Indeed, PPIs, among the numerous azole derivatives, are considered to be strong sensitizers via topical exposure [66]. In contrast, oral or systemic exposure is less frequently 


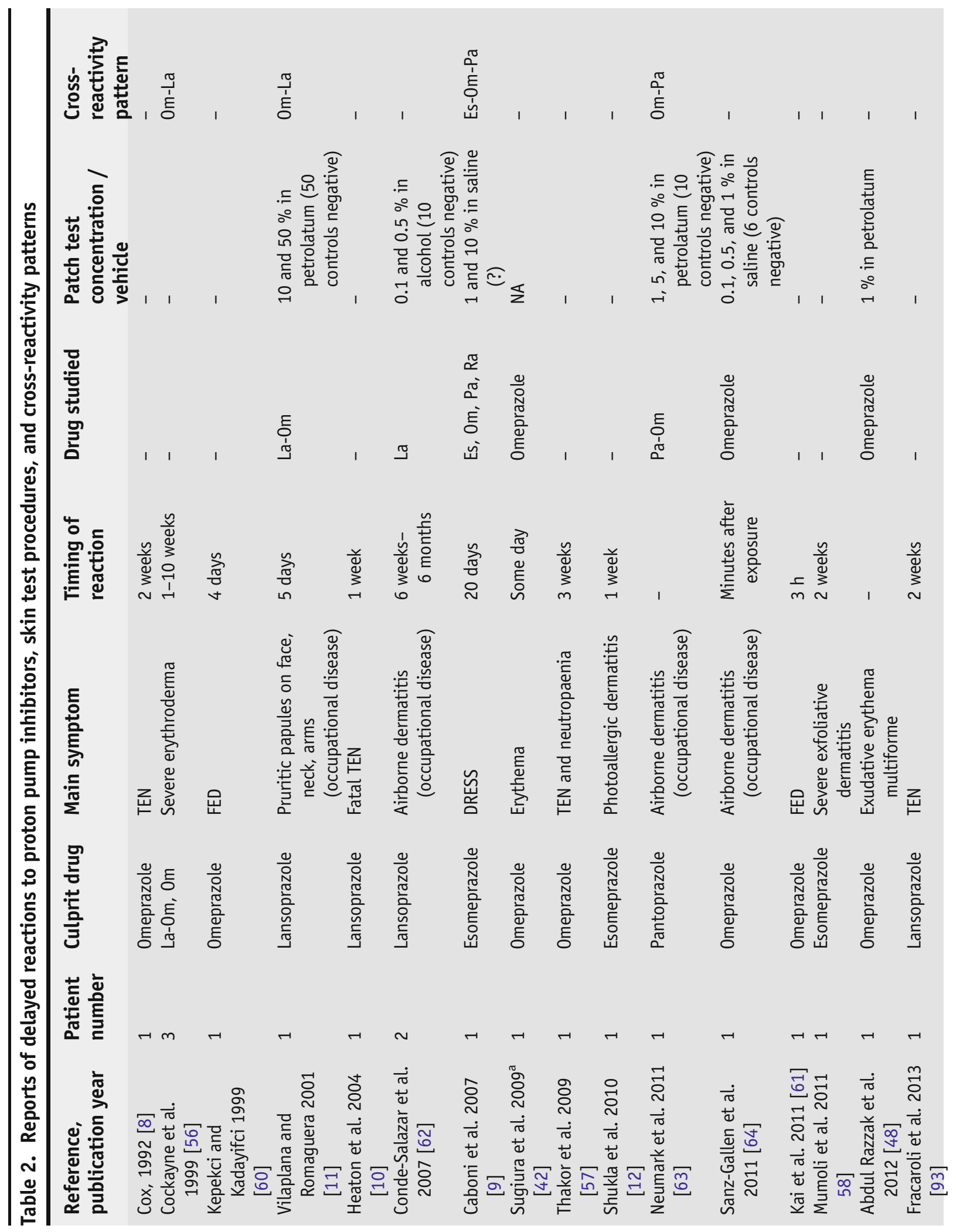




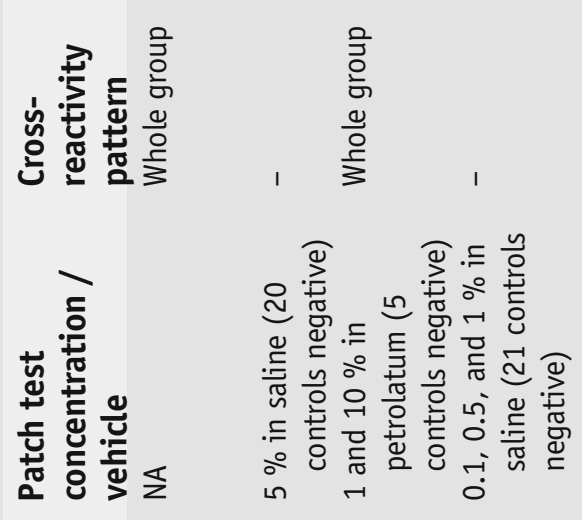

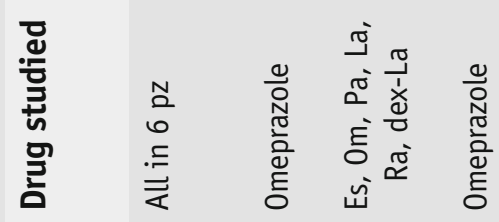

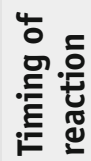

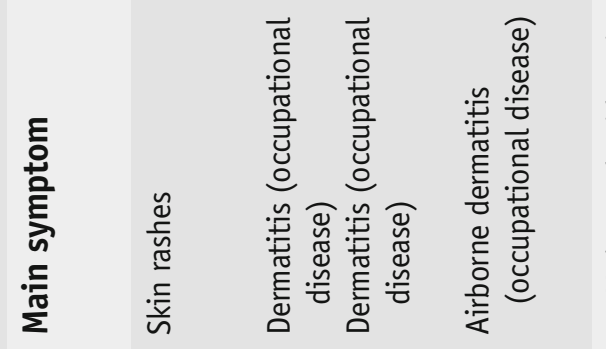

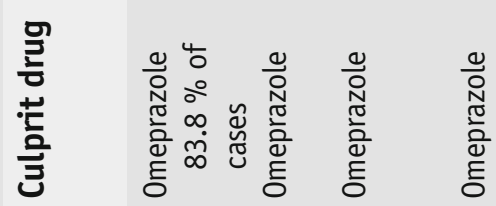

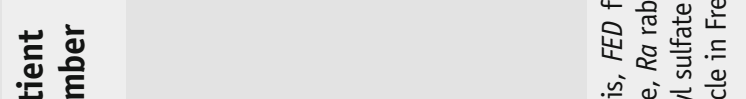

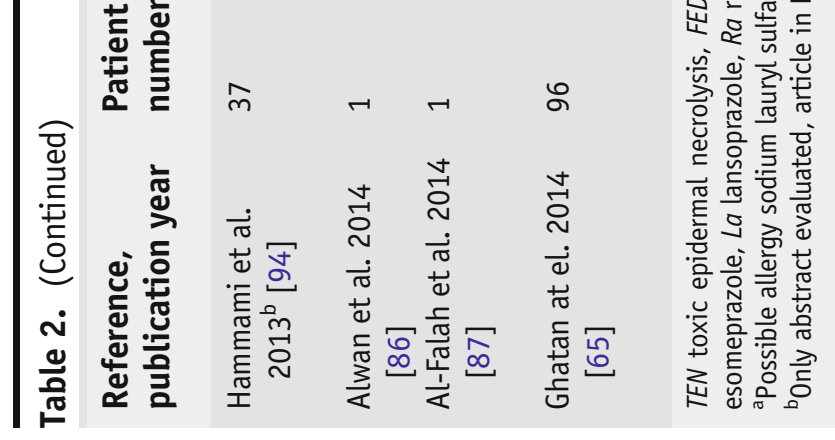


associated to the development of eczematous symptoms. Therefore, direct contact of PPI formulation with the skin should be avoided.

\section{Diagnostic procedures}

In patients with suspected drug allergy, the diagnosis is usually based on skin testing and, when indicated, oral provocation test (OPT) [67, 68].

Nevertheless, skin tests are often not carried out due to the paucity of information on the adequate and nonirritant concentration to be used. Thus, a diagnosis is made only on the basis of clinical history or of the positivity of oral provocation test, which could not discriminate between immunomediated or non immuno-mediated reactions. This is the case of the first reports on PPIs HSRs [69-73].

The first diagnostic protocol for immediate reactions to omeprazole and lansoprazole was published in 1999 [13]. Afterward, many other case reports with diagnostic procedures limited to some PPI have been published [52, 53, 74-76].

In 11 of the papers, the authors performed skin test with all the PPIs available, with the exception of dexlansoprazole and tenatoprazole, to assess the pattern of cross-reactivity. Among these reports, skin prick test (ST) and intradermal test (ID) protocols differ subtly in the considered nonirritant

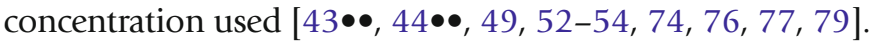

Some authors also performed ID with lansoprazole and rabeprazole that are available only for oral administration. Oral preparations for cutaneous tests are usually crushed and diluted in saline solution, but this procedure could have produced false positive results $[49,52,54,74]$.

Bonadonna et al. reported a clinical study on the diagnostic accuracy of skin test (ST and ID) vs OPTs including 40 patients with mild to moderate immediate reactions. The authors reported a specificity and a positive predictive value (PPV) of $100 \%$, whereas the sensitivity and the negative predictive value (NPV) were 61.3 and $91.9 \%$ respectively. The positive and negative likelihood ratios were 61.3 and 0.39 [43••]. The recommended nonirritant concentration for ST was $40 \mathrm{mg} / \mathrm{mL}$ for omeprazole, esomeprazole, pantoprazole, and rabeprazole and $30 \mathrm{mg} / \mathrm{mL}$ for lansoprazole, while the maximum concentration used for ID was $0.4 \mathrm{mg} / \mathrm{mL}$ for omeprazole, esomeprazole, and pantoprazole $[43 \bullet \bullet, 80]$. It is not recommended to perform IDs with solutions obtained from oral preparations due to the risk of false positive results.

The study by Kepil Ozdemir confirmed the satisfactory specificity $(100 \%)$ and PPV (100 \%), with lower values of sensitivity (58.8\%) and NPV (70.8\%) [44••].

Skin tests are overall safe; no adverse reaction during skin test performance with PPI has been reported so far. A single study suggests that the probability of confirming an IgE-mediated mechanism with cutaneous test decreases over time as happens with beta-lactams and highlights the importance of studying drug allergy as early as possible [54].

Serum specific IgE to PPIs cannot be assayed by ELISA or radioallergosorbet tests $[13,81]$.

It has been proposed that basophil activation test (BAT) might help in the diagnosis of IgE-mediated allergic reactions to PPIs in two case reports [77, 82]. 
Patch tests have been performed by using different drug concentration (from 0.1 to $50 \%$ ) and vehicles (petrolatum, saline and, in one case report, alcohol), and nonirritant reactions were reported in healthy controls by all authors $[9,11$, $48,62-65,86,87]$.

In a case report of DRESS following treatment with esomeprazole, a mild flare-up of skin symptoms appeared $60 \mathrm{~h}$ after patch test, which lasted for 4 days, and suggest to be careful in testing patients with severe delayed reactions [9].

A suggestive clinical history and the temporal relationship is critical in the diagnosis of HSRs to PPIs, in fact, IgE-mediated HSRs may appear also later than $1 \mathrm{~h}$ from the drug exposure. Skin tests (ST and ID) are safe and highly specific for the diagnosis of IgE-mediated HSRs and should be always performed; OPTs should be performed under close medical control in case of skin test negative results.

In the case of possible cell-mediated HSRs, a delayed reading of IDs, at least after 24 and $48 \mathrm{~h}$, and patch test should be performed [67].

Studies on diagnostic accuracy of skin test and patch test on the diagnosis of cell-mediated HSRs to PPIs are still missing.

\section{Treatment options}

\section{Desensitization treatment}

There is a single case report describing a successful oral desensitization treatment in a 44-year-old man with recurrent anaphylaxis after omeprazole exposure [83].

Intradermal tests performed with omeprazole and pantoprazole were positive. Because the treatment with a PPI was mandatory for the patient, an oral desensitization treatment was performed.

Granules of omeprazole capsules were dissolved in bicarbonate to create serial tenfold dilutions (the lowest was $0.002 \mathrm{mg} / \mathrm{ml}$ ).

The treatment was started with $0.001 \mathrm{mg}$ and in 18 escalating doses, administered every $20 \mathrm{~min}$, the final dose of $32.665 \mathrm{mg}$ was reached in $5.6 \mathrm{~h}$. Afterward, patient could continue the treatment with omeprazole $20 \mathrm{mg}$ twice daily.

IDs with omeprazole and pantoprazole repeated after the treatment resulted to be reduced.

Since the first studies on immediate HSRs published in 1999, the possible crossreactivity among PPIs has been described and confirmed by skin test results. Only 11 authors have performed a complete evaluation of all PPIs for studying cross-reactivity $[45,46,49,52-54,74,76-79]$.

According to the published articles, it is possible to identify four different patterns of cross-reactivity among PPIs:

- Whole group hypersensitivity: patients with allergy to all PPIs [49, 52, 54, 77].

- Pattern A: patients with allergy to omeprazole, esomeprazole and pantoprazole but tolerating lansoprazole and rabeprazole $[45,47,48$, 82].

- Pattern B: patients with allergy to lansoprazole and rabeprazole but tolerating omeprazole, esomeprazole, and pantoprazole [45, 74, 75]. 
- Pattern C: patients with selective sensitization to a single PPI and who tolerate other PPIs [53, 76, 77, 79, 84].

These patterns could be explained by the chemical structure of PPIs that are modified benzimidazoles with a pyridine ring that differs in substitutions on both rings, as suggested by some authors [ $54,47,75]$.

Omeprazole, esomeprazole, and pantoprazole have changes in their benzimidazole rings, whereas lansoprazole and rabeprazole have their modification in the pyridine ring. Isolated cases of concomitant sensitization to theoretically

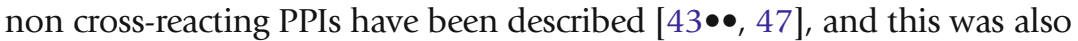
observed in one large study where the most common pattern of cross-reactivity was between lansoprazole and pantoprazole [46].

A possible cross-reactivity between PPIs and other benzimidazoles derivatives (mebendazole, domperidone, and mizolastine) have been postulated, but the only two studies performed so far have excluded this possibility by means of skin tests and OPTs $[48,85]$.

Considering the good accuracy of skin test, mainly in immediate-type HSRs, a complete evaluation of all PPIs is a useful tool to identify possible safe alternatives in patients that need therapy with a PPI. In case of negative skin tests, an OPT is mandatory.

\section{Compliance with Ethics Guidelines}

\section{Conflict of Interest}

Carla Lombardo declares that she has no conflict of interest.

Patrizia Bonadonna declares that she has no conflict of interest.

Human and Animal Rights and Informed Consent

This article does not contain any studies with human or animal subjects performed by any of the authors.

\section{References and Recommended Reading}

Papers of particular interest, published recently, have been highlighted as:

- Of importance

$\bullet$ Of major importance

1. Thomson ABR, Sauve MD, et al. Safety of the long-term use of proton pump inhibitors. World J Gastroenterol. 2010;16:2323-30.

2. $\quad$ Chang YS. Hypersensitivity reactions to proton pump inhibitors. Curr Opin Allergy Clin Immunol. 2012;12:348-53.

This review provides a comprehensive overview of allergic and nonallergic hypersensitivity reactions to PPIs.

3. Koury SI, Stone CK, la Charitè DD. Omeprazole and the development of acute hepatitis. Eur J Emerg Med. 1998;5:467-9.
4. Yip D, Kovac S, Jardine M, et al. Omeprazole-induced interstitial nephritis. J Clin Gastroenterol. 1997;25:450-2.

5. Ricketson J, Kimel G, Spence J, et al. Acute allergic interstitial nephritis after use of pantoprazole. CMAJ. 2009; 180:535-8.

6. Gouraud A, Vochelle V, Descotes J, et al. Proton pump inhibitors induced neutropenia: possible cross-reactivity between omeprazole and pantoprazole. 2007. Clin Drug Investig. 2010;30:559-63. 
7. $\quad$ Lowe G, Henderson CL, Grau RH. A systematic review of drug induced subacute cutaneous lupus erythematous. Br J Dermatol. 2011;164:465-72.

An interesting systematic review of drug induced subacute cutaneous lupus erythematosus (SCLE) focusing in possible differences between drug-induced SCLE and idiopathic SCLE.

8. Cox NH. Acute dissemined epidermal necrosis due to omeprazole. Lancet. 1992;340:857.

9. Caboni S, Gunera-Saad N, Ktiouet-Abassi S, et al. Esomeprazole-induced DRESS syndrome. Studies of cross-reactivity among proton pump inhibitor drugs. Allergy. 2007;62:1342-3.

10. Heaton NR, Edmonds EVJ, Francis ND, et al. Fatal toxic epidermal necrolysis due to lansoprazole. Clin Exp Dermatol. 2004;29:612-3.

11. Vilaplana J, Romaguera C. Allergic contact dermatitis due to lansoprazole, a proton pump inhibitor. Contact Dermatitis. 2001;44:47.

12. Shukla A, Mahapatra A, Gogtay N, et al. Esomeprazoleinduced photoallergic dermatitis. J Postgrad Med. 2010;56:229-31.

13. Galindo PA, Borja J, Feo F, et al. Anaphylaxis to omeprazole. Ann Allergy Asthma Immunol. 1999;82:52-4.

14. Ottervanger JP, Phaff RA, Vermeulen EG, et al. Anaphylaxis to omeprazole. J Allerg Clin Inmunol. 1996;97:1413-4.

15. Chen J, Yuan YC, Leontiadis GI, et al. Recent safety concerns with proton pump inhibitors. J Clin Gastroenterol. 2012;46:93-114.

This review on the safety of long term therapy with PPIs focuses on 3 possible concerns: interaction with clopidogrel therapy, the risk of spontaneous fractures and of hypomagnesemia.

16. Fock KM, Ang TL, Bee LC, et al. Proton pump inhibitors: do differences in pharmacokinetics translate into differences in clinical outcomes? Clin Pharmacokinet 2008;47:1-6.

17. Aslam N, Wright R. Dexlansoprazole MR. Expert Opin Pharmacother 2009; 2329-36.

18. Vakily M, Zhang W, Wu J, et al. Pharmacokinetics and pharmacodynamics of a known active PPI with a novel dual delayed release technology, dexlansoprazole MR: a combined analysis of randomized controlled clinical trials. Curr Med Res Opin. 2009;25:627-38.

19. Vestergaard P, Rejnmark L, Mosekilde L. Proton pump inhibitors, histamine $\mathrm{H} 2$ receptor antagonists, and other antacid medicationsand the risk of fracture. Calcif Tissue Int. 2006;79:76-83.

20. Corley DA, Kubo A, Zhao W, et al. Proton pump inhibitors and histamine-2 receptor antagonists are associated with hip fractures among at-risk patients. Gastroenterology. 2010;139:93-101.

21. Kaye JA, Jick H. Proton pump inhibitors use and risk of hip fractures in patients without major risk factors. Pharmacotherapy. 2008;28:951-9.

22. Targownik LE, Lix LM, Leung S, et al. Proton pump inhibitors use is not associated with osteoporosis or accelerated bone mineral density loss. Gastroenterology. 2010;138:896-904.
23. Ngamruengphong S, Leontiadis GI, Radhi S, et al. Proton pump inhibitors and risk of fractures: a systematic review and meta-analysis of observational studies. Am J Gastroenterol.

2011;106:1209-19.

24. Broeren MA, Geerdink EA, Vader HL, et al. Hypomagnesemia induced by several proton-pump inhibitors. Ann Intern Med. 2009;151:755-6.

25. Cundy T, Dissanayake A. Severe hypomagnesemia in long-term users of proton pumo inhibitors. Clin Endocrinol (Oxf). 2008;69:338-41.

26. Hoorn EJ, van der Hoek J, de Man RA, et al. A case series of proton pump inhibitor-induced hypomagnesemia. Am J Kidney Dis. 2010;56:112-6.

27. Dial MS. Proton pump inhibitors use and enteric infenctions. Am J Gastroenterol. 2009;104:S10-6.

28. Vakil N. Acid inhibition and infections outside the gastrointestinal tract. Am J Gastroenterol. 2009;104:S17-20.

29. Sultan N, Nazareno J, Gregor J. Association between proton pump inhibitors and respiratory infections: a systematic review and meta-analysis of clinical trials. Can J Gastroenterol. 2008;22:761-6.

30. Jalving M, Koornsta JJ, Wesseling J, et al. Increased risk of fundic gland polyps during long-term proton pump inhibitor therapy. Aliment Pharmacol Ther. 2006;24:1341-8.

31. Jalving M, Koornsta JJ, Gotz JM, et al. High-grade dysplasia in sporadic fundic gland polyps: a case report and review of the literature. Eur J Gastroenterol Hepatol. 2003;15:1229-33.

32. Pali-Scholl I, Jensen-Jarolim E. Anti-acid medication as risk factor for food allergy. Allergy. 2011;66:469-77.

33. Untersmayr E, Jensen-Jarolim E. The role of protein digestibility and antacids on foods allergy outcomes. J Allergy Clin Immunol. 2008;121:1301-8.

34.• Wolbing F, Fischer J, Koberle M, et al. About the role and underlying mechanisms of cofactors in Anaphylaxis. Allergy. 2013;66:1085-92.

This review is an interesting overview of possible eliciting factors of anaphylaxis in sensitised but clinically tolerant patients.

35. Untersmayr E, Scholl I, Swodoba I, et al. Antacid medication inhibits digestion of dietary proteins and causes food allergy: a fish allergy model in $\mathrm{BALB} / \mathrm{c}$ mice. J Allergy Clin Immunol. 2003;112:616-23.

36. Diesner SC, Knittelfelder R, Krishnamurthy D, et al. Dose-dependent food allergy induction against ovoalbumine under acid-suppression: a murine food allergy model. Immunol Lett. 2008;121:45-51.

37. Untersmayr E, Bakos N, Scholl I, et al. Anti-ulcer drugs promote IgE formation toward dietary antigens in adult patients. FASEB J. 2005;19:656-8.

38. Ramirez E, Cabanas R, Laserna LS, et al. Proton pump inhibitors are associated with hypersensitivity reactions to drugs in hospitalised patients: a nested case-control in a retrospective cohort study. Clin Exp Allerg. 2013;43:344-52. 
39. Riemer AB, Gruber S, Pali-Scholl, et al. Suppression of gastric acid increases the risk of developing immunoglobulin E-mediated drug hypersensitivity: human diclofenac sensitization and a murine sensitization model. Clin Exp Allerg. 2010;40:486-93.

40. Park BK, Naisbitt DJ, Gordon SF, et al. Metabolic activation in drug allergies. Toxicology. 2001;158:11-23.

41. Haeney M. Angio-oedema and urticaria associated with omeprazole. Br Med J. 1992;305:860.

42. Sugiura K, Sugiura M, Kawabe Y, et al. Delayed-type hypersensitivity reactions due to sodium lauryl sulphate in omeprazole. J Eur Acad Dermatol Venereol. 2009;23:610-1.

43.• Bonadonna P, Lombardo C, Bortolami O, et al. Hypersensitivity to proton pump inhibitors: diagnostic accuracy of skin tests compared to oral provocation test. J Allergy Clin Immunol. 2012;130:547-9.

In this large multicenter study the accuracy of skin tests compared to oral provocation tests in immediate-type HSRs has been assessed. An optimal specificity (100\%) and PPV (100\%) were found with good sensitivity (61.3\%) and NPV (91.9\%). 44.• Kepil Özdemir S, Yılmaz I, Aydin Ö, et al. Immediatetype hypersensitivity reactions to proton pump inhibitors: usefulness of skin tests in the diagnosis and assessment of cross-reactivity. Allergy. 2013;68:1008-14.

This large study confirms the satisfactory specificity (100\%) and PPV (100\%) of skin tests in diagnosis of IgE-mediated allergy, but found lower values of sensitivity (58.8\%) and NPV (70.8\%).

45. Bose S, Guyer A, Long A, et al. Evaluation and management of hypersensitivity to proton pump inhibitors. Ann Allergy Asthma Immunol. 2013;111:452-7.

46. Tayman $\mathrm{C}$, Mete E, Catal F, et al. Hypersensitivity reaction to omeprazole in a child. JACI. 2009;19:76-7.

47. Lobera T, Navarro B, Del Pozo MD, et al. Nine cases of omeprazole allergy: cross-reactivity between proton pump inhibitors. J Investig Allergol Clin Immunol. 2009;19:57-60.

48. Abdul Razzak E, Tomás M, Tornero P, et al. Nine cases of allergy to omeprazole. J Investig Allergol Clin Immunol. 2012;22:228-30.

49. Sánchez-Morillas L, Rojas Pérez-Ezquerra P, González Mendiola R, et al. Eleven cases of omeprazole hypersensitivity: diagnosis and study of cross-reactivity. J Investig Allergol Clin Immunol. 2014;24:130-2.

50. Kollmeier AP, Eddleston J, Zuraw BL, et al. Recurrent anaphylaxis linked to pantoprazole. J Allergy Clin Immunol. 2004;114:975-7.

51. Garmendia Zallo M, Sanchez Azkarate A, Kraemer Mbula R, et al. Existe reactividad cruda entre inhibidores de la bomba de protones? Allerg Immunophatol. 2004;32:92-5.

52. Garrido S, Cumplido JA, Rabano A, et al. Allergy to proton pump inhibitors: diagnosis and assessment of cross-reactivity. J Investig Allergol Clin Immunol. 2008; 18:136-42.

53. Vovolis V, Koutsostathis N, Stefanaki E. IgE-mediated anaphylaxis to proton pump inhibitors- cross-reacting study. Allergy. 2008;63:1251-2.
54. Sobrevia Elfau MT, Garces Sotillos M, Ferrer Claveria L, et al. Study of cross-reactivity between proton pump inhibitors. J Investig Allergol Clin Immunol. 2010;20:157-61.

55. Aksu K, Kurt E. anaphylaxis to lansoprazole with tolerance to omeprazole. Allergol Immunopathol. 2012;40:393-4.

56. Cockayne SE, Glet RJ, Gawkrodger DJ, et al. Severe erythrodermic reactions to the proton pump inhibitors omeprazole and lansoprazole. Br J Dermatol. 1999;141:173-5.

57. Thakor AS, Burke A, Handfield-Jones S, et al. Toxic epidermal necrolysis and neutropaenia: complications of omeprazole. Australas J Dermatol. 2009;50:207-10.

58. Mumoli N, Luschi R, Camaiti A, et al. Severe exfoliative dermatitis caused by esomeprazole. J Am Geriatr Soc. 2011;59:2377-8.

59. Domínguez-Leñero V, Barrera-Ledesma M, RomeroAlonso M, et al. Stevens-Johnson syndrome and toxic hepatitis due to esomeprazole. Farm Hosp. 2009;33:118-9.

60. Kepekci Y, Kadayifci A. Fixed drug eruption in hands caused by omeprazole. Int J Clin Pharmacol Ther. 1999;376:307-9.

61. Kai Y, Okamoto O, Fujiwara S. Fixed drug eruption caused by three unrelated drugs: promethazine, pethidine and omeprazole. Clin Exp Dermatol. 2011;36:755-8.

62. Conde-Salazar L, Blancas-Espinosa R, Pérez-Hortet C. Occupational airborne contact dermatitis from omeprazole. Contact Dermatitis. 2007;56:44-6.

63. Neumark M, Ingber A, Levin M, et al. Occupational airborne contact dermatitis caused by pantoprazole. Contact Dermatitis. 2011;64:60-1.

64. Sanz-Gallén P, Nogué S, Herrera-Mozo I, et al. Occupational contact allergy to omeprazole and fluoxetine. Contact Dermatitis. 2011;65:18-9.

65. Ghatan PH, Marcusson-Ståhl M, Matura M, et al. Sensitization to omeprazole in the occupational setting. Contact Dermatitis. 2014;71:371-5.

66. Hausen BM, Lucke R, Rothe E, et al. sensitizing capacity of azole derivatives: part III. Investigations with anthelmintics, antimycotics, fungicides, antithyroid compounds, and proton pump inhibitors. Am J Contact Dermat. 2000;11:80-8.

67. Brockow K, Romano A, Blanca M, et al. General considerations for skin test procedures in the diagnosis of drug hypersensitivity. Allergy. 2002;57:45-51.

68. Aberer W, Bircher A, Romano A, et al. Position paper: drug provocation testing in the diagnosis of drug hypersensitivity reactions: general considerations. Allergy. 2003;58:854-63.

69. Perez-Roldan F, Lorda de Los Rios I, Quinzanos ER, et al. Lansoprazole and glottis edema. Am J Gastroenterol. 1999;94:1995.

70. Natsch S, Vinks MH, Voogt AK, et al. Anaphylactic reactions to proton pump inhibitors. Ann Pharmacother. 2000;34:474-6. 
71. Ricciardi L, Fedele R, Mazzeo L, et al. Adverse reactions to pantoprazole. Scand J Gastroenterol. 2003;38:800.

72. Gratacos L, Soy D, Lluis M, et al. Apparent anaphylaxis associated with lansoprazole. Am J Health Syst Pharm. 2005;62:1388-9.

73. Choi SV, Han JM, Bae YJ, et al. Lessons from two cases of anaphylaxis to proton pump inhibitors. J Clin Pharm Ther. 2012;37:614-6.

74. Porcel S, Rodriguez A, Jimenez S, et al. Allergy to lansoprazole: study of cross-reactivity among proton pump inhibitors. Allergy. 2005;60:1087-8.

75. Perez Pimiento A, Prieto lastra L, Rodriguez Cabreros MI, et al. J Allergy Clin Immunol. 2006;117:707-8.

76. Vovolis K, Christogianni N, Koutsostathis N. Immunoglobulin E-mediated anaphylaxis to rabeprazole. J Investig Allergol Clin Immunol. 2010;20:352-63.

77. Stefanaki EC, Vovolis V, Letsa I, et al. Anaphylactic reaction to omeprazole. Am J Gastroenterol. 2008;103:1581-3.

78. Perez-Ezquerra R, Sanchez Morillas L, Laguna Martinez JJ, et al. Allergol Immunophatol (Madr). 2010;39:54.

79. Karabacak E, Kutlu A, Aydin E, et al. Hypersensitivity to lansoprazole with tolerance to other proton pump inhibitors: does cross-reactivity between proton pump inhibitors really exist? Allergol Immunophatol (Madr). 2013;41:136-7.

80. Brockow, Garvey LH, Aberer W, et al. Skin test concentrations for systemically administered drugs - an ENDA/EAACI drug allergy interest group position paper. Allergy. 2013;702.

81. González P, Soriano V, López P, et al. Anaphylaxis to proton pump inhibitors. Allergol Immunopathol. 2002;30:342-3.

82. Gamboa PM, Sanz ML, Urrutia I, et al. CD63 expression by flow cytometry in the in vitro diagnosis of allergy to omeprazole. Allergy. 2003;58:538-9.
83. Confino-Cohen R, Goldberg A. Anaphylaxis to omeprazole: diagnosis and desensitization protocol. Ann Allergy Asthma Immunol. 2006;96:33-6.

84. Fardet L, Izzedine H, Ciroldi M, et al. Pantoprazoleinduced recurrent anaphylactic shock. Am J Gastroenterol. 2002;97:1578-9.

85. Gonzalo-Garijo MA, Jimenez-Ferrera G, BobadillaGonzales P, et al. Hypersensitivity reactions to mizolastine: study of cross reactions. J Investig Allergol Clin Immunol. 2006;16:391-3.

86. Alwan W, Banerjee P, White IR. Occupational contact dermatitis caused by omeprazole in a veterinary medicament. Contact Dermatitis. 2014;71:376-82.

87. Al-Falah K, Schachter J, Sasseville D. Occupational allergic contact dermatitis caused by omeprazole in a horse breeder. Contact Dermatitis. 2014;71:377-8.

88. Bowlby HA, Dickens GR. Angioedema and urticaria associated with omeprazole confirmed by drug rechallenge. Pharmacotherapy. 1994;14:119-22.

89. Kaatz M, Bauer A, Hipler C, et al. Nonallergic anaphylaxis to pantoprazole. Allergy. 2002;57:184.

90. Demirkan K, Bozkurt B, Karakaya G, et al. Anaphylactic reaction to drugs commonly used for gastrointestinal system diseases: 3 case reports and review of the literature. J Investig Allergol Clin Immunol. 2006;16:203-9.

91. Vlahos NP, Vavilis GK, Giannelou AG, et al. Hypersensitivity to proton pump inhibitors: lansoprazoleinduced Kounis syndrome. Int J Cardiol. 2009;134:e94-6.

92. Lai HC, Hsu SW, Lu CH, et al. Anaphylaxis to pantoprazole during general anesthesia. J Anesth. 2011;25:606-8.

93. Fracaroli TS, Miranda LQ, Sodré JL, et al. Toxic epidermal necrolysis induced by lansoprazole. An Bras Dermatol. 2013;88:117-20.

94. Hammami S, Affes H, Ksouda K, et al. Study of cross reactivity between proton pump inhibitors. Therapie. 2013;68:361-8. 